\section{SIGNIFICANCE OF ABSENT ANKLE PULSE}

BY

\section{J. LUDBROOK, Ch.M., F.R.C.S., F.R.A.C.S. Lecturer in Surgery}
A. M. CLARKE, M.B., Ch.B.
Assistant Lecturer in Surgery

AND

\section{J. K. McKENZIE, M.B., M.R.A.C.P. Assistant Lecturer in Medicine University of Otago}

The inability to detect the pulsation of the posterior tibial artery behind the internal malleolus, or of the dorsalis pedis artery, is widely used as an important physical sign. In the patient with symptoms or signs of ischaemia of the foot, the absence of pulses is regarded as highly significant. On the other hand, the incidental discovery of an impalpable ankle pulse in a patient who does not present with an ischaemic foot is given widely varying interpretations by different clinicians. The finding may be dismissed as an observer error. The anatomical course of the artery may be thought to be anomalous. In older age-groups the absent pulse may be regarded as merely evidence. of ageing, or it may be taken as a sign of atherosclerosis.

Several widely quoted studies have been undertaken to estimate the proportion of impalpable ankle pulses in normal subjects (Kramer, 1933 ; Morrison, 1933 ; Reich, 1934 ; Silverman, 1946). The dorsalis pedis pulse is held to be impalpable in from 0\% (Kramer, 1933) to $12.4 \%$ (Silverman, 1946) of normal limbs, and the posterior tibial pulse in from $2.8 \%$ (Silverman, 1946) to $12.8 \%$ (Morrison, 1933). The dorsalis pedis pulse is said to be misplaced in $8 \%$ of limbs (Reich, 1934). It has been stated that the peroneal artery replaces the posterior tibial in 5\% of cases (Aird, 1957).

Perusal of the details of these studies suggests reasons for these wide divergencies of opinion. The "normal " subjects are variously diabetics (Kramer, 1933), males with an average age of 20 years (Silverman, 1946), or healthy people of unspecified age (Reich, 1934) or of unspecified sex in the different age-groups (Morrison, 1933). In each study there seems to have been but a single observer, and when large numbers of subjects are examined in a short time-for example, Silverman (1946) - the question is raised of what constitutes an impalpable pulse.

The implication of the differing subjective and objective interpretations of the impalpable ankle pulse in subjects without other evidence of atherosclerosis or ischaemic disease of the foot is that in our present state of knowledge no significance at all can be assigned to the finding.

We set out to re-examine the question of impalpable ankle pulses in " normal " subjects with certain objects in view. We hoped to arrive at some estimate of the observer error, at least between trained observers, and to redetermine the frequency of impalpable pulses in different age-and-sex groups. - We sought also to determine with what degree of certainty the apparent absence of an ankle pulse could be taken as evidence of arterial disease.

\section{Method}

Population Examined.-It was apparent that, except in the younger age-groups, the assembly of a normal population presented great difficulties. As the purpose of this study was basically to examine the ankle pulses of those presenting to the doctor with other than ischaemic disease of the legs or general atherosclerosis, a selected hospital population was used as "normal" subjects. The criteria for selection were that the patient should not have been admitted primarily for cardiac or peripheral vascular disease, cerebral vascular disease, or diabetes mellitus. Of the 239 subjects, $88 \%$ were from surgical wards. There was no significant difference in the proportion of patients with absent pulses whether they were in medical or in surgical wards.

Technique.-All patients were examined lying in bed with a room temperature of from 17 to $20^{\circ} \mathrm{C}$. The three observers worked independently of each other but examined each group of patients at the same time. There was no pressure of time so far as each examination was concerned, and an average of five minutes was spent by each observer with each subject. Where a pulse was apparently impalpable the observer spent up to 10 minutes in his examination. The results were compared at the end of each batch of patients, but re-examination of the patients was not permitted. As a routine, an attempt was made to detect the posterior tibial and dorsalis pedis pulses in each foot. No record was kept of minor variations in the position of either of these arteries. No attempt was made to feel the pulse of the perforating branch of the peroneal artery unless one or other of the posterior tibial or dorsalis pedis pulses was undetectable. The popliteal and femoral pulses were sought only when no pulses could be felt in the foot. The technique adopted by all three observers when there was difficulty in detecting a pulse was to explore with the fingers of one hand while those of the other felt the subject's radial or femoral pulse. The sometimes recommended technique of feeling one's own radial pulse to distinguish between digital pulsation and the pulse sought was found to be of little value.

$\chi^{2}$ was used to test the statistical significance of the various findings.

\section{Results}

Observer Error.-Despite the very great care which each observer took when he was unable readily to detect an ankle pulse, it is apparent that a considerable observer error exists. This has been assessed as the probability that if one observer is unable to detect a pulse the other two observers will agree with him (Table I). It can be seen that for the dorsalis pedis pulse in all age-groups the observer error is high, and there is no more than an even chance that when one observer finds this pulse missing the other two observers will agree with him. On the other hand, for the posterior tibial pulse it can be seen that the observer error becomes significantly less with increasing age $(P<0.0001)$, and in the over-60 age-group is very small indeed.

TABLE I.-Probability that if One Observer Cannot Detect a Pulse the Two Other Observers will Agree with Him

\begin{tabular}{c|c|c}
\hline \multirow{2}{*}{ Age-group } & \multicolumn{2}{|c}{ Probability of Agreement } \\
\cline { 2 - 3 } & Posterior Tibial & Dorsalis Pedis \\
\hline $0-19$ & $\overline{0.50}$ & 0.57 \\
$20-39$ & 0.13 & 0.50 \\
$40-59$ & 0.85 & 0.42 \\
$60-79$ & 0.57
\end{tabular}


Systematic Observer Error.-From Table II it can be seen that there is a suggestion that A. M.C. is able to detect fewer pulses than J.K. McK., and J. K. McK. fewer than J. L. The difference is far from significant, however $(\mathrm{P}>0.2)$.

TABLE II.-Number of Pulses Undetectable by Each Observer

\begin{tabular}{c|c|c|c}
\hline Observer & Posterior Tibial & Dorsalis Pedis & Total \\
\hline A.M.C... & 27 & 54 & 81 \\
J.K. McK. & 24 & 51 & 75 \\
J.L. & 18 & 46 & 64 \\
\hline
\end{tabular}

Pulses Missing in Different Age-groups.-Meaningful analysis of this is difficult. We believe that an observer who could feel a pulse which the remaining two could not was as likely to be in error as when he could not feel a pulse which the other two could - that is, it was not reasonable to accept a pulse as absent only when all three could not feel it or even when a majority could not. The results of all three observers were therefore pooled and expressd as the number of observations when a pulse could not be found, as compared with the total number of observations (see Table III). In the case of the dorsalis pedis pulse, in the under- 20 agegroup $8.7 \%$ were impalpable. With increasing age there was a significant increase in the proportion of pulses found missing $(0.001<\mathrm{P}<0.01)$, principally in the

Table III.-Pulse Impalpable, by Sex and Age

\begin{tabular}{|c|c|c|c|c|c|}
\hline \multirow{2}{*}{$\begin{array}{l}\text { Age- } \\
\text { group }\end{array}$} & \multirow{2}{*}{ Sex } & \multirow{2}{*}{$\begin{array}{c}\text { No. of } \\
\text { Limbs } \\
\text { Examined }\end{array}$} & \multirow{2}{*}{$\begin{array}{c}\text { No. of } \\
\text { Observa- } \\
\text { tions }\end{array}$} & \multicolumn{2}{|c|}{$\begin{array}{c}\text { No. of Impalpable Pulses } \\
\text { Observed }\end{array}$} \\
\hline & & & & Post. Tib. & D. Pedis \\
\hline \multirow[t]{2}{*}{$0-19\{$} & $\mathbf{F}$ & $\begin{array}{l}81 \\
60\end{array}$ & $\begin{array}{l}243 \\
180\end{array}$ & $\begin{array}{l}\mathbf{0} \\
\mathbf{1}\end{array}$ & $\begin{array}{l}17 \\
20\end{array}$ \\
\hline & Total & 141 & 423 & $1(0 \cdot 2 \%)$ & $37(8 \cdot 7 \%)$ \\
\hline \multirow[t]{2}{*}{$20-39$} & $\underset{\mathbf{F}}{\mathbf{M}}$ & $\begin{array}{l}53 \\
55\end{array}$ & $\begin{array}{l}159 \\
165\end{array}$ & $\begin{array}{l}4 \\
2\end{array}$ & $\begin{array}{l}24 \\
12\end{array}$ \\
\hline & Total & 108 & 324 & $6(1.9 \%)$ & $36(11 \cdot 1 \%)$ \\
\hline \multirow[t]{2}{*}{$40-59$} & $\underset{\mathbf{F}}{\mathbf{M}}$ & $\begin{array}{l}75 \\
68\end{array}$ & $\begin{array}{l}225 \\
204\end{array}$ & $\begin{array}{r}5 \\
18\end{array}$ & $\begin{array}{l}24 \\
12\end{array}$ \\
\hline & Total & 143 & 429 & $23(5 \cdot 4 \%)$ & $36(8.4 \%)$ \\
\hline \multirow{2}{*}{$60-79$} & $\underset{\mathbf{F}}{\mathbf{M}}$ & $\begin{array}{l}47 \\
34\end{array}$ & $\begin{array}{l}141 \\
102\end{array}$ & $\begin{array}{l}18 \\
21\end{array}$ & $\begin{array}{l}32 \\
10\end{array}$ \\
\hline & Total & 81 & 243 & $39(16.0 \%)$ & $42(17 \cdot 3 \%)$ \\
\hline
\end{tabular}

over-60 age-group. On the other hand, in the case of the posterior tibial pulse only $0.24 \%$, were impalpable in the under-20 age-group, but there was a very significant increase in this figure with increasing age $(P<0.0001)$, again most notable in the over-60 age-group.

Sex Difference in Impalpable Pulses (Table III).In the 40-59 age-group there is a strikingly higher proportion of impalpable posterior tibial pulses in females $(0.001<\mathrm{P}<0.01)$, which is not noted in other age-groups.

Peroneal Pulse (perforating branch of peroneal artery).-It was extremely rare to be able to feel a peroneal pulse if the posterior tibial pulse was impalpable, except in males of the 60-79 age-group (Table IV).

TABLE IV.-Probability that if a Posterior Tibial or Dorsalis Pedis Pulse is Impalpable a Peroneal Pulse is Detectable

\begin{tabular}{c|c|c}
\hline \multirow{2}{*}{ Age-group } & \multicolumn{2}{|c}{ Probability of Palpable Peroneal Pulse } \\
\cline { 2 - 3 } & $\begin{array}{c}\text { Posterior Tibial } \\
\text { Impalpable }\end{array}$ & $\begin{array}{c}\text { Dorsalis Pedis } \\
\text { Impalpable }\end{array}$ \\
\hline $0-19$ & 0 & 0.27 \\
$20-39$ & $0 \cdot 17$ & 0.22 \\
$40-59$ & 0 & $0 \cdot 14$ \\
$60-79$ & 0.28 & 0.19 \\
\hline
\end{tabular}

On the other hand, a more or less constant $20 \%$ of peroneal pulses were palpable at all ages when the dorsalis pedis was impalpable.

Popliteal Pulse.-In only one subject, a male in the 40-59 age-group, was a popliteal pulse undetectable, and that in both legs. In this subject all observers agreed that the dorsalis pedis pulse in both legs and the posterior tibial in one were undetectable. Femoral pulses were present.

Difference Between Right and Left Legs.-There was no significant difference between right and left legs with respect to impalpable pulses $(P>0.05)$.

\section{Discussion}

By definition, the decision whether a given pulse is palpable or not is a purely subjective one, and cannot be substantiated by any objective method of recording the pulse or blood-flow. The expression of the results of this study therefore presented a certain difficulty. The method adopted of pooling the results of all three observers provides in fact an arithmetic mean. As the three observers could not be distinguished so far as skill is concerned (Table II), this seems at first sight reasonable and to represent the average findings of one observer. This method of expression is, however, limited, for it takes no account of the fact that one observer's population of pulseless limbs is very different from another's. This point is, however, at least in part covered by the expression of observer error (Table I).

In the under-20 age-group, who might reasonably be supposed to be free of atherosclerosis, the posterior tibial pulse was essentially always palpable. This is in contrast to several reported studies (Table V) and may represent a racial difference, chance, or perhaps a reflection of the very careful examinations performed by the observers in this study.

TABLE V.-Comparative Incidence of Impalpable Pulses in Different Series of "Normal" Subjects

\begin{tabular}{|c|c|c|c|}
\hline & & $\begin{array}{c}\text { Posterior Tibial } \\
\text { Impalpable } \\
(\%)\end{array}$ & $\begin{array}{c}\text { Dorsalis Pedis } \\
\text { Impalpable } \\
(\%)\end{array}$ \\
\hline $\begin{array}{l}\text { Kramer (1933) } \\
\text { Morrison (1933) } \\
\text { Reich (1934) } \\
\text { Silverman (1946) } \\
\text { Present series ... }\end{array}$ & $\begin{array}{l}. \\
\because \\
\because \\
.\end{array}$ & $\begin{array}{l}12 \cdot 8 \\
5 \cdot 8 \\
2 \cdot 8 \\
0 \cdot 24\end{array}$ & $\begin{array}{c}0 \\
8 \cdot 8 \\
4 \\
12 \cdot 4 \\
8.7\end{array}$ \\
\hline
\end{tabular}

The figure of $8.7 \%$ in the same age-group for impalpable dorsalis pedis pulses does, however, agree better with the "normal" values of other workers (Table V). With one exception, however (Morrison, 1933), none of these series is in any way comparable with the present one, in that the criteria of normality, age, and sex are unspecified.

So far as the pulsation of the perforating branch of the peroneal artery is concerned, we found no evidence in the younger age-groups that this pulse and the posterior tibial vary inversely, as has been suggested (Aird, 1957), though in the younger age-groups this pulse was palpable in about $20 \%$ of instances when the dorsalis pedis was not.

The most striking observation is the very great observer error with respect to the detection of ankle pulses (Table I). The magnitude of this did not diminish during the course of the study, and therefore seems independent of acquired skill. This is a manifestation of the entirely subjective nature of the observation of 
ankle pulses, and suggests that with one reservation the inability to detect an ankle pulse by one observer is quite without significance, unless the finding is confirmed by careful examination by other observers. The reservation is with respect to the posterior tibial pulse in the over-60 age-group, where there is a very much higher probability that the single observer's findings will be confirmed.

There is, however, evidence that under certain circumstances the incidental finding of an absent ankle pulse may be of significance.

It can be seen (Table III) that the upward trend with age of the proportion of impalpable pulses is most striking in the case of the posterior tibial pulse. On the other hand, in the over-40 age-groups a preponderance of undetectable posterior tibial pulses occurred in females (Table III), which is unexpected if this is taken as an indication of arterial disease. In the 40-59 agegroup, however, the observer error is very great (Table I). This we attributed to the high proportion of women in this age-group with a fat-pad behind the internal malleolus.

If the proportion of absent posterior tibial pulses in the different age-groups is recalculated on a basis of the findings when all three observers agree, a rather different result is obtained (Table VI). TABLE VI.-Percentage of Limbs with Impalpable Posterior
Tibial Pulses in Different Age-groups. The Results of One Observer, Compared with those when Three Observers Agree

\begin{tabular}{c|c|c}
\hline Ago-group & One Observer & Three Observers Agree \\
\hline $0-19$ & $0.2 \%$ & $0 \%$ \\
$20-39$ & $1.9 \%$ & $0.9 \%$ \\
$40-59$ & $50.4 \%$ & $0.7 \%$ \\
$60-79$ & $16.0 \%$ & $13.6 \%$ \\
\hline
\end{tabular}

Thus of the 392 limbs of subjects under the age of 60 which were examined, all three observers agreed in being unable to feel a posterior tibial pulse in only $0.5 \%$. If three observers of similar skill are unable to detect the posterior tibial pulse in a limb the probability is therefore very high that this represents an abnormality.

It is difficult to escape the conclusion that in some $13.6 \%$ of the limbs of those over the age of 60 such an abnormality existed. When it is remembered that this is a finding with which all three observers agreed, it is very difficult to explain it on a basis other than that of atheromatous narrowing or block of the artery. There is no absolute proof of this ; nor, indeed, would any proof except arteriographic or necropsy findings be satisfactory.

\section{Summary}

The great observer error in the detection of the posterior tibial and dorsalis pedis pulses is demonstrated.

In the limbs of subjects under the age of 20 , on the average a single observer failed to detect $0.24 \%$ of posterior tibial pulses and $8.7 \%$ of dorsalis pedis pulses.

In patients not presenting primarily with atherosclerosis the lack of significance of inability to detect the dorsalis pedis pulse is shown.

Evidence is produced that if three independent observers are unable to detect the posterior tibial pulse there is a high degree of probability that an abnormality is present.

We thank Mr. G. F. S. Spears for assistance with the statistical analysis.

\section{REFERENCES}

Aird, I. (1957). Companion in Surgical Studies, 2nd ed. Livingstone, Edinburgh

Kramer, D. W. (1933). Amer. J. med. Sci., 185, 402.

Morrison, H. (1933). New Engl. J. Med., 208, 438.

Reich, R. S. (1934). Ann. Surg., 99, 613.

Silverman, J. J. (1946). Amer. Heart J., 32, 83.

\section{THERAPEUTIC TRIALS IN MULTIPLE SCLEROSIS}

FINAL REPORT ON EFFECTS OF INTRATHECAL INJECTION OF TUBERCULIN (P.P.D.)

BY

HENRY G. MILLER, M.D., F.R.C.P.

D. J. NEWELL, M.A., Ph.D., F.S.S. Statistician

ALAN R. RIDLEY, M.B., M.R.C.P.

AND

KURT SCHAPIRA, M.D.

Research Fellows

From the Department of Neurology and the Medical Research Council Research Group on Demyelinating Diseases, Royal Victoria Infirmary, and Medical School, Newcastle upon Tyne

In a previous communication (Miller, Newell, Ridley, and Schapira, 1961) the preliminary results were reported of a controlled trial of treatment with intrathecal P.P.D., which Smith, Espir, Whitty, and Russell (1957) had suggested might have a beneficial effect on the course of multiple sclerosis. At that time 82 of the intended 90 patients had been included in the trial, and the mean period between treatment and first assessment was 15 months. It was concluded that patients given intrathecal P.P.D. did not fare better than those who received intrathecal saline or others who had merely been subjected to lumbar puncture. This was also the experience of Kelly and Jellinek (1961) ; nor could Colover, Kremer, Lovelace, and Silver (1962) find any evidence from their uncontrolled observations that intrathecal P.P.D. had a favourable influence on the disease. Marshall and O'Grady (1959) investigated the changes in spinal fluid after the administration of intrathecal P.P.D. in multiple sclerosis and other chronic neurological diseases, but refrained from commenting on the therapeutic effect because of the small number of patients with multiple sclerosis in their series and the lack of controls. The present report is concerned with the follow-up trial of 90 trial patients reviewed annually for one to three years after treatment.

\section{Material}

The 90 patients were allocated to one of three treatment groups-lumbar puncture (L.P.), saline (S.), and P.P.D.- by a system of stratified randomization. Each patient was given a functional grade. The grades were grade I, symptom-free; grade II, with symptoms but unrestricted activities ; grade III, moderately restricted ; grade IV, markedly restricted; grade V, confined to home ; grade VI, immobile at home; grade VII, bedridden. A separate randomization was carried out in 